\title{
ANÁLISE DE CRESCIMENTO EM AMENDOINZEIRO (ARACHIS HYPOGAEA L.) SUBMETIDO À MATOCOMPETIÇÃO ${ }^{1}$
}

Aceito em 01.10.92. Recebido 02.08.94.

\author{
Luiz Mauro Barbosa ${ }^{2}$ \\ Robinson Antonio Pitelli ${ }^{3}$ \\ José Marcos Barbosa ${ }^{2}$
}

\begin{abstract}
RESUMO - (Análise de crescimento em amendoinzeiro (Arachis hypogaea L.) submetida à matocompetição). Foram verificados os efeitos de diferentes períodos de controle e convivência de plantas daninhas $(0 ; 14 ; 28 ; 42 ; 56 ; 70 ; 84$ e 98 dias) na cultura do amendoinzeiro (Arachis hypogaea L.) em Moji-Guaçu (SP). As principais espécies invasoras da área experimental foram: Acanthospermum australe (Loef.) O. Kuntz, Waltheria indica L., Borreria alata DC., Richardia scabra L., Rhynchelytrum repens (Nees) Stapf. et Hubb. e Diodia teres Walt. De maneira geral, durante quase todo o ciclo, a espécie de maior importância relativa foi $A$. australe, sendo suplantada por outras espécies apenas na colheita, quando já estava encerrando seu ciclo de desenvolvimento. $O$ período inicial de controle das plantas daninhas, além de reduzir a densidade da comunidade infestante, diminuiu sua riqueza em espécies e alterou a importância relativa das populações. A matocompetição resultou na redução do crescimento do amendoinzeiro, principalmente a partir de 42 dias de convivência, afetando a altura das plantas, a área foliar, o índice de área foliar e o acúmulo epígeo de matéria seca. Não foram afetados os números de ramos e de folíolos por planta, nem a qualidade dos grãos e o vigor das sementes do amendoim. A produção de frutos foi reduzida ao redor de $31,5 \%$ em decorrência da interferência das plantas daninhas. O período total de prevenção da interferência na produção foi de 14 dias e o período anterior à interferência foi de 70 dias.
\end{abstract}

Palavras-chave: Fitomassa, componentes da produção, avaliação do crescimento, germinação.

\begin{abstract}
Analysis of peanut growth under a weed control). Effects of different periods (014-28-42-56-70-84 and 98 days) of weed control in peanut plants (Arachis hypogaea L.) were studied in Moji-Guaçu region (State of São Paulo). The main weed species in the experimental area were: Acanthospermum australe (Loef.) O. Kuntz, Waltheria indica L.; Borreria alata D.C.; Richardia scabra L.; Rhynchelytrum repens (Ness) Stapf. et Hubb and Diodia teres Walt. During the whole peanut life cycle, except at harvest time, the most important weed species was $A$.
\end{abstract}

1 Trabalho realizado no Setor de Reservas Biológicas e Estação Experimental de Moji-Guaçu, Seção de Ecologia, Instituto de Botânica de São Paulo. Apresentado no XLI Congresso Nacional de Botânica, Fortaleza, CE.

2 Instituto de Botânica. Caixa Postal 4005, 01051, São Paulo, Brasil.

${ }^{3}$ Departamento de Biologia Aplicada, FCAV/UNESP. Campus de Jaboticabal. Jaboticabal, SP. 
australe. The initial period of weed control decreased the density of the weed community, as well as the number of species and modified the relative importance of populations. After 42 days the weed competition had affected the peanut development by reducing plant growth, leaf area, leaf area index and epigeal storage of dry matter. The number of twigs and of leaflets per plant, and the quality and vigour of seeds were not affected. The peanut pod productivity decreased $31,5 \%$ in the presence of weeds. The total period avoiding interference in the production was 14 days and the period before the interference was 70 days.

Key-words: phytomass, production components, growth assessment, germination.

\section{Introdução}

Apesar de ser uma das principais leguminosas cultivadas no Brasil e apresentar inúmeras vantagens como opção para rotação de cultura, o amendoinzeiro (Arachis hypogaea L.) tem, ainda hoje, uma rentabilidade considerada muito baixa. Por isso, não há boa expectativa para utilização de modernas técnicas do controle químico e/ou cultural, que envolvem elevados gastos. Daí a preocupação dos pesquisadores no estabelecimento de sistemas racionais de manejo da vegetação infestante da cultura. No entanto, faltam informações básicas a respeito dos mecanismos de interferência sofrida pela cultura e das épocas em que esta interferência torna-se crítica.

Os efeitos da matocompetição no crescimento, desenvolvimento e produtividade das espécies cultivadas, que se alteram em decorrência da competição das plantas daninhas têm sido investigadas intensamente nos últimos anos.

Segundo Blanco (1972), o grau de competição sofrido por determinada espécie cultivada depende da intervenção de fatores ligados à própria cultura (espécie e cultivar, espaçamento e densidade de semeadura), à comunidade infestante (composição específica, densidade e distribuição) e ao ambiente em que se desenvolve a interação. Neste último, devem-se considerar as alterações culturais impostas pelo homem nos agroecossistemas. Blanco (1972) considera ainda, de extrema importância, a extensão do período de convivência de cultura e mato, associando-se também a localização deste período no ciclo da cultura. Pitelli (1983) sugere como formas de interferência da comunidade infestante a alelopatia; a competição por fatores de desenvolvimento das plantas; as dificuldades impostas na colheita, secagem e armazenamento dos grãos e os efeitos na qualidade do produto colhido.

Hauser \& Parham (1969), Drenan \& Jennings (1977) e York \& Coble (1977) verificaram que a densidade de plantas daninhas constitui-se fator determinante no grau de competição. Estes dois últimos autores comentam também sobre as variações na capacidade de recrutamento de recursos do meio, impostas por alterações na composição específica das plantas daninhas.

A matocompetição pode ser incrementada ou minimizada na cultura do amendoim com a utilização de determinadas práticas culturais, conforme foi verificado por Bianco (1978), Pitelli et al. (1981) e Barbosa (1989); ou ainda por alterações nas condições climáticas regionais (Feakin, 1973, Hamdoun, 1977).

O período em que a cultura do amendoinzeiro deve ser mantida livre da 
competição de plantas daninhas é muito variável e depende, em grande parte do ano agrícola e das condições locais. Tais fatos, em muitos casos propiciam divergências marcantes entre diferentes pesquisas realizadas (Hauser et al. 1975; Buchanan et al. 1976; Pacheco 1977; Drenan \& Jennings 1977; Pitelli et al. 1981; Barbosa 1989). Apenas estes fatores já justificam a realização do presente trabalho, que faz parte de um elenco maior de investigação, onde procurou-se verificar os efeitos de diferentes períodos de convivência e controle de plantas daninhas sobre os principais parâmetros de análise de crescimento da planta de amendoinzeiro e qualidade do produto colhido (frutos e grãos).

\section{Material e métodos}

O ensaio foi instalado e conduzido na Reserva Biológica e Estação Experimental de Moji-Guaçu (22¹8'S e 471' 'W), no município de Moji-Guaçu (SP). A altitude média é de $600 \mathrm{~m}$, apresenta topografia relativamente plana e o clima é do tipo Cwa Köppen (Struffaldi De-Vuono et al., 1982).

O preparo do solo ocorreu de maneira convencional, com aração e gradagem, e o plantio foi efetuado manualmente no espaçamento de $0,60 \mathrm{~m}$ entre sulcos de semeadura, utilizando-se 20 sementes de cultivar "tatu-53" semeadas por metro linear do sulco e cobrindo-se com cerca de 2 centímetros de terra. Na semeadura foram aplicados $50 \mathrm{~kg} / \mathrm{ha}$ de sulfato de amônio, $50 \mathrm{~kg} / \mathrm{ha}$ de cloreto de potássio e $450 \mathrm{~kg} / \mathrm{ha} \mathrm{de}$ termofosfato magnesiano, com base em análise prévia do solo.

A cultura não exigiu tratos culturais complementares e as plantas daninhas foram controladas apenas nos tratamentos propostos para a pesquisa.

O ensaio foi locado segundo o delineamento experimental de blocos casualizados, com quatro repetições, sendo as parcelas experimentais constituídas de 6 linhas de semeadura com $5 \mathrm{~m}$ de comprimento, sendo duas utilizadas como bordadura, uma para estudos de análise de crescimento e as três centrais para dados de produção.

Os tratamentos constituíram-se de diferentes épocas e períodos de convivência e de controle da comunidade infestante, e foram divididos em dois grupos (G1 e G2), sendo que no primeiro a cultura foi submetida a períodos crescentes de convivência (a partir de $75 \%$ de emergência das plântulas) com a comunidade infestante, ou seja, 0 , 14, 28, 42, 46, 70, 84 e 98 dias de desenvolvimento da cultura. Após cada período de convivência, as parcelas foram mantidas no limpo até o final do ciclo (100 a 110 dias). No segundo grupo de tratamentos, as parcelas foram mantidas livres da presença da comunidade infestante por períodos equivalentes aos do primeiro grupo, após o que foi suprimido o controle.

Para os estudos fitossociológicos de plantas daninhas, foram realizados levantamentos pelo método do "quadrado de amostragem", avaliando-se $1 \mathrm{~m}^{2}$ na área útil das parcelas, correspondentes às duas sub-amostragens de $0,5 \mathrm{~m}^{2}$. Estas determinações foram efetuadas no primeiro grupo (G1), ao final de cada período de convivência e no segundo grupo (G2), por ocasião da colheita do amendoim. Foram calculados para cada população, a densidade relativa, as freqüências absoluta e relativa, a dominância 
relativa, o índice do valor de importância e a importância relativa, através de fórmulas apropriadas como as utilizadas por Barbosa (1989):

a) Densidade relativa

$\mathrm{DR}=\frac{\mathrm{Ne}}{\mathrm{Nt}} \times 100(\%)$, onde Ne é o número de indivíduos de uma determinada espécie encontrada nas amostragens e Nt é o número total de indivíduos amostrados.

b) Freqüência absoluta

NAe

$\mathrm{FA}=\frac{1}{\mathrm{NAt}} \times 100(\%)$, onde NAe é o número de amostragens em

que ocorreu uma determinada espécie e NAt é o número total de amostragens efetuadas.

c) Freqüência relativa

$\mathrm{FR}=\frac{\mathrm{FAe}}{\mathrm{FAt}} \times 100(\%)$, onde FAe refere-se à frequiência

absoluta de uma determinada espécie e FAt é a somatória das frequiências absolutas de todas as espécies da comunidade infestante.

d) Dominância relativa

$\mathrm{DoR}=\frac{\mathrm{MSe}}{\mathrm{MSt}} \times 100(\%)$, onde MSe refere-se ao peso da

matéria seca acumulada por uma determinada espécie e MSt é o peso da matéria seca acumulada por toda a comunidade.

e) Índice de valor de importância

$\mathrm{IVI}=\mathrm{DR}+\mathrm{FR}+\mathrm{DoR}$

f) Importância relativa

IVIe

IR $=\longrightarrow \times 100(\%)$, onde IVIe refere-se ao índice de valor IVIt

de importância de uma determinada população e IVIt é a somatória dos índices de 
valor de importância de todas as populações componentes da comunidade.

Os efeitos da comunidade infestante sobre o crescimento do amendoinzeiro foram verificados com a coleta de 15 plantas da cultura por parcela a cada 14 dias, nos tratamentos em que eram encerrados os períodos de convivência e de controle das plantas daninhas. As coletas ocorreram na linha reservada para obtenção de amostras para análise de crescimento.

Em laboratório, procedeu-se à separação e contagem de folíolos, frutas e hastes e a medidas de comprimento para a maior haste de cada planta. Em cada parcela amostraram-se aleatoriamente 50 folíolos, que foram moldados em papel de seda, para estimar a área foliar. A área de cobertura foliar das 15 plantas foi estabelecida através de planimetragem dos 50 folíolos de cada uma, realizada com planímetro tipo A. OTT. Kempten Gayern, modelo 311, e do peso da matéria seca total dos folíolos coletados em cada parcela. Assim, foram determinados em amendoinzeiro: número de folíolos (NF); número de hastes (Nh); altura da planta (H); peso seco dos folíolos (PSF); área foliar (AF) e peso da matéria seca total (PMSt).

A partir dos valores obtidos para área foliar e peso da matéria seca, foram calculados os principais parâmetros da análise de crescimento de acordo com Pitelli (1987) e Barbosa (1989):

$\left(\mathrm{AF}_{\mathrm{n}}-\mathrm{AF}_{\mathrm{n}-1}\right)$ : diferença entre áreas foliares obtidas em duas amostragens sucessivas, variável.

a) Índice de Área Foliar (IAF)

$\mathrm{IAF}=\frac{\mathrm{AF}}{\mathrm{S}}$, que exprime a área foliar $(\mathrm{AF})$ por unidade de

área de solo (S), constante, igual a $04 \mathrm{dm}^{2}$, estabelecido com base no espaçamento entre linhas $(0,60 \mathrm{~m})$ e número de plantas mantidas na linha de plantio após o desbaste (15 plantas por metro linear).

b) Razão de Área Foliar (RAF)

$\mathrm{RAF}=\frac{\mathrm{AF}}{\mathrm{Pt}} \mathrm{dm}^{2} \cdot \mathrm{g}^{-1}$, que relaciona área foliar com peso seco

total da planta.

c) Taxa de Crescimento Absoluto (TCA)

TCA $=\frac{\left(\mathrm{Pt}_{\mathrm{n}}-\mathrm{Pt}_{\mathrm{n}-1}\right)}{\left(\mathrm{T}_{\mathrm{n}}-\mathrm{T}_{\mathrm{n}-1}\right)} \mathrm{g} \cdot \mathrm{dia}^{-1}$, que exprime o crescimento da

planta, em peso $\left(\mathrm{Pt}_{\mathrm{n}}-\mathrm{Pt}_{\mathrm{n}-1}\right)$ entre duas amostragens consecutivas $\left(\mathrm{T}_{\mathrm{n}}-\mathrm{T}_{\mathrm{n}-1}\right)$.

d) Taxa de Produção de Matéria Seca (TPMS) 
TPMS $=\frac{\left(\mathrm{Pt}_{\mathrm{n}}-\mathrm{Pt}_{\mathrm{n}-1}\right)}{\mathrm{S} \cdot\left(\mathrm{T}_{\mathrm{n}}-\mathrm{T}_{\mathrm{n}-1}\right)} \mathrm{g} \cdot \mathrm{dm}^{-2} \cdot \mathrm{dia}^{-1}$

e) Taxa de Crescimento Relativo (TCR)

TCR $=\frac{\left(\ln \mathrm{Pt}_{\mathrm{n}}-\ln \mathrm{Pt}_{\mathrm{n}-1}\right)}{\left(\mathrm{T}_{\mathrm{n}}-\mathrm{T}_{\mathrm{n}-1}\right)} \mathrm{g} \cdot \mathrm{g}^{-1} \cdot \mathrm{dia}^{-1}$, onde $\ln =$ logarítmo

neperiano durante um período de crescimento $\left(T_{n}-T_{n-1}\right)$, e TCR representa o incremento no peso, por unidade de peso no início do período, por dia.

f) Taxa Assimilatória Líquida (TAL)

TAL $=\frac{\left(\mathrm{Pt}_{\mathrm{n}}-\mathrm{Pt}_{\mathrm{n}-1}\right)}{\left(A F_{n}-A F_{n-1}\right) \cdot\left(\ln A F_{n}-\ln A F_{n-1}\right) \cdot\left(T_{n}-T_{n-1}\right)} \mathrm{g} \cdot \mathrm{dm}^{-2} \cdot \mathrm{dia}^{-1}$, que

representa a capacidade da planta em aumentar o peso em termos da área de sua superfície assimilatória, por dia (em geral relaciona-se com a eficiência fotossintética da planta).

Para verificar os efeitos das plantas daninhas sobre a qualidade das sementes, foram realizados testes de germinação e índice de velocidade de germinação (IVG) para 100 sementes de cada tratamento (Barbosa, 1983).

\section{Resultados e discussão}

Acanthospermum australe (Loef.) O. Kuntz foi a espécie que apresentou maior densidade relativa durante toda a fase de crescimento do amendoinzeiro, em convivência com a comunidade infestante, sendo superada pelas demais espécies apenas por ocasião da colheita da cultura (Figura 1), provavelmente devido ao seu ciclo mais curto que os das demais espécies. Isto pode ser constatado na maioria dos trabalhos revisados (Bianco 1978; Pitelli 1980; Pansani 1983; Martins 1988). A riqueza específica verificada na área foi muito baixa, sendo ainda reduzida nas últimas avaliações. Além de A. australe, as principais espécies componentes da comunidade infestante foram Rhynchelytrum repens (Ness) Stapf. et Hubb, Richardia scabra L., Waltheria indica L., Borreria alata DC. e Diodia teres Walt. A partir da amostragem aos 42 dias, as espécies só apareceram co-habitando na amostragem aos 84 dias (Figura 1), podendo este fato estar associado ao incremento na interferência interespecífica.

Os principais índices fitossociológicos da comunidade infestante também foram analisados por ocasião da colheita em parcelas mantidas no limpo por períodos crescentes no início da cultura e, inversamente, períodos decrescentes de convivência 

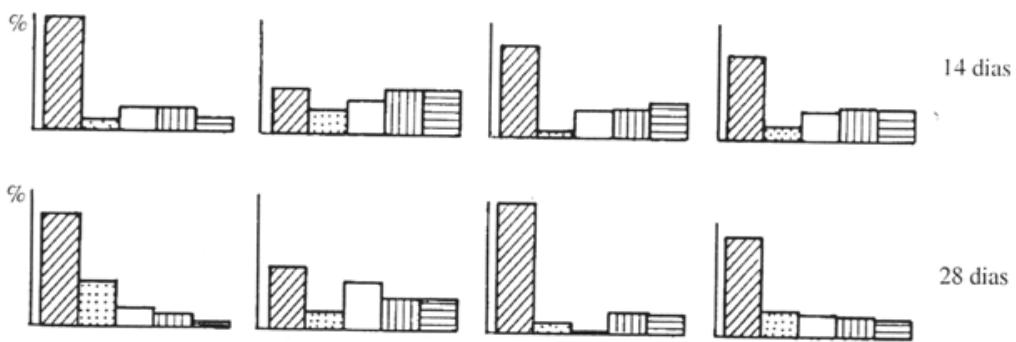

28 dias
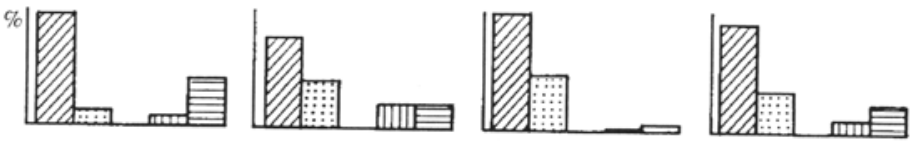

42 dias
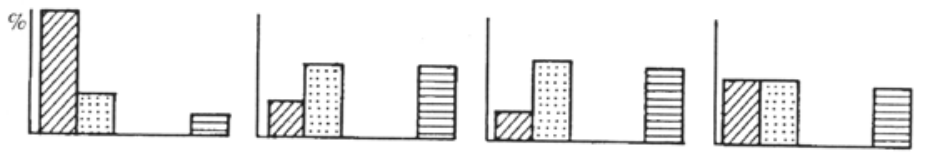

56 dias
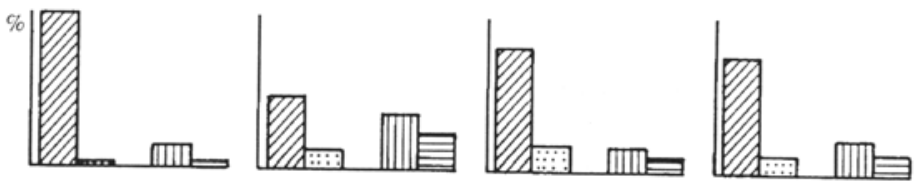

70 dias
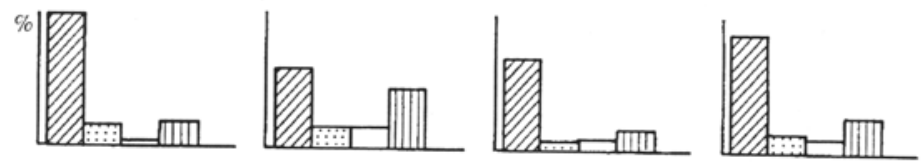

84 dias
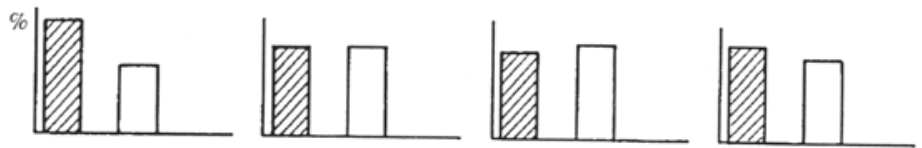

98 dias

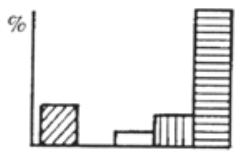

Densidade

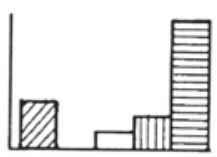

Frequêência

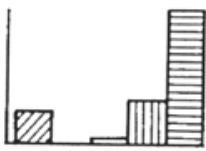

Dominância

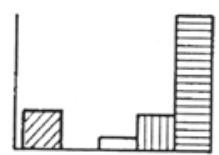

Importância

D Acanthospermum australe (Loef.) O. Kuntze

Rhynchelitrum repens (Nees) Stapf. et Hubb.

$\square$ Richardia Scraba L. $\equiv$ Outras

IIII] Waltheria indica $\mathrm{L}$.

Figura 1 - Densidade, freqüência, dominância e importância relativas das principais espécies componentes da comunidade infestante de plantio de amendoim em Mogi-Guaçu - 1985/86, amostrada com tempos crescentes de convivência a partir da emergência das plântulas. 
com a comunidade infestante (Figura 2). Aos 14 dias, houve grande equilíbrio entre $A$. australe e R. scabra; aos 42 dias, o equilíbrio foi entre A. australe e R. repens. Alguns resultados são de difícil interpretação, como por exemplo, algumas espécies que emergiram, em um período e não em outro, como ocorreu aos 84 dias com A. australe. Uma hipótese é que tal fato esteja relacionado com a dormência de sementes e/ou mecanismos evolutivos de preservação das espécies de plantas daninhas. Há grande deficiência de estudos básicos sobre os mecanismos que inibem ou desencadeiam o processo germinativo na maioria das espécies, especialmente das que ocorrem em países tropicais.

Apenas nas duas primeiras avaliações da análise de crescimento, o número de hastes observado nas parcelas sob matocompetição apresentaram valores estatisticamente superiores ao observado nas parcelas mantidas livres da comunidade infestante (Figura $3 \mathrm{~A}$ ). Como reação primária à incipiente interferência das plantas daninhas, o amendoinzeiro aloca mais recursos à brotação lateral, responsável pela formação de hastes. Noda (1977) observou comportamento semelhante em arroz, que inicialmente aumentou o perfilhamento e Pitelli \& Neves (1978) observaram que em soja também ocorreu maior crescimento inicial das plantas cultivadas. A partir de 42 dias do ciclo da cultura, a interferência das plantas daninhas reduziu a altura das plantas (Figura 3B), possivelmente devido a uma pressão que levara à redução da dominância apical com o conseqüente desenvolvimento de ramos laterais. Embora os efeitos da comunidade infestante não tenham sido significativos a partir dos 42 dias (Figura 3A), ocorreu um maior número de hastes nas parcelas em convivência com a comunidade infestante (no mato). Parece provável (e merece ser melhor pesquisado) que, sob interferência das plantas daninhas, o amendoinzeiro apresenta ligeira mudança de arquitetura com maior número de ramificações mais curtas.

A comunidade infestante não afetou significativamente o número de folíolos do amendoinzeiro, em qualquer época de amostragem (Figura 4A). No entanto, o crescimento destes folíolos parece ter sido afetado significativamente a partir dos 56 dias, porque a partir desta época observou-se significativa redução da área foliar (Figura 4B). Aos 98 dias, já em intensa senescência foliar, não foi observada diferença significativa entre as duas condições de cultivo a que foi submetida a cultura. Como o índice de área foliar foi baseado num valor fixo de superfície do solo $\left(4 \mathrm{dm}^{2}\right)$, os resultados são rigorosamente semelhantes aos observados para área foliar.

Aos 56 e 98 dias do ciclo do amendoinzeiro houve influência da comunidade infestante no acúmulo de matéria seca total da planta (Figura 5A). De um modo geral, a manifestação quantitativa de todas as características ou parâmetros estudados na cultura foi máxima aos 70 dias, indicando ser esta a época de maior produtividade biológica da planta. $\mathrm{O}$ padrão de acumulação de matéria seca pelas plantas do amendoinzeiro (Figura 5A), quando comparado com os efeitos na altura da planta (Figura 3B) e na área foliar (Figura 4B), indica alterações na arquitetura epígea da planta, quando em competição, sugerindo maior alocação de recursos na formação de hastes.

Não houve influência significativa das plantas daninhas na razão da área foliar, 


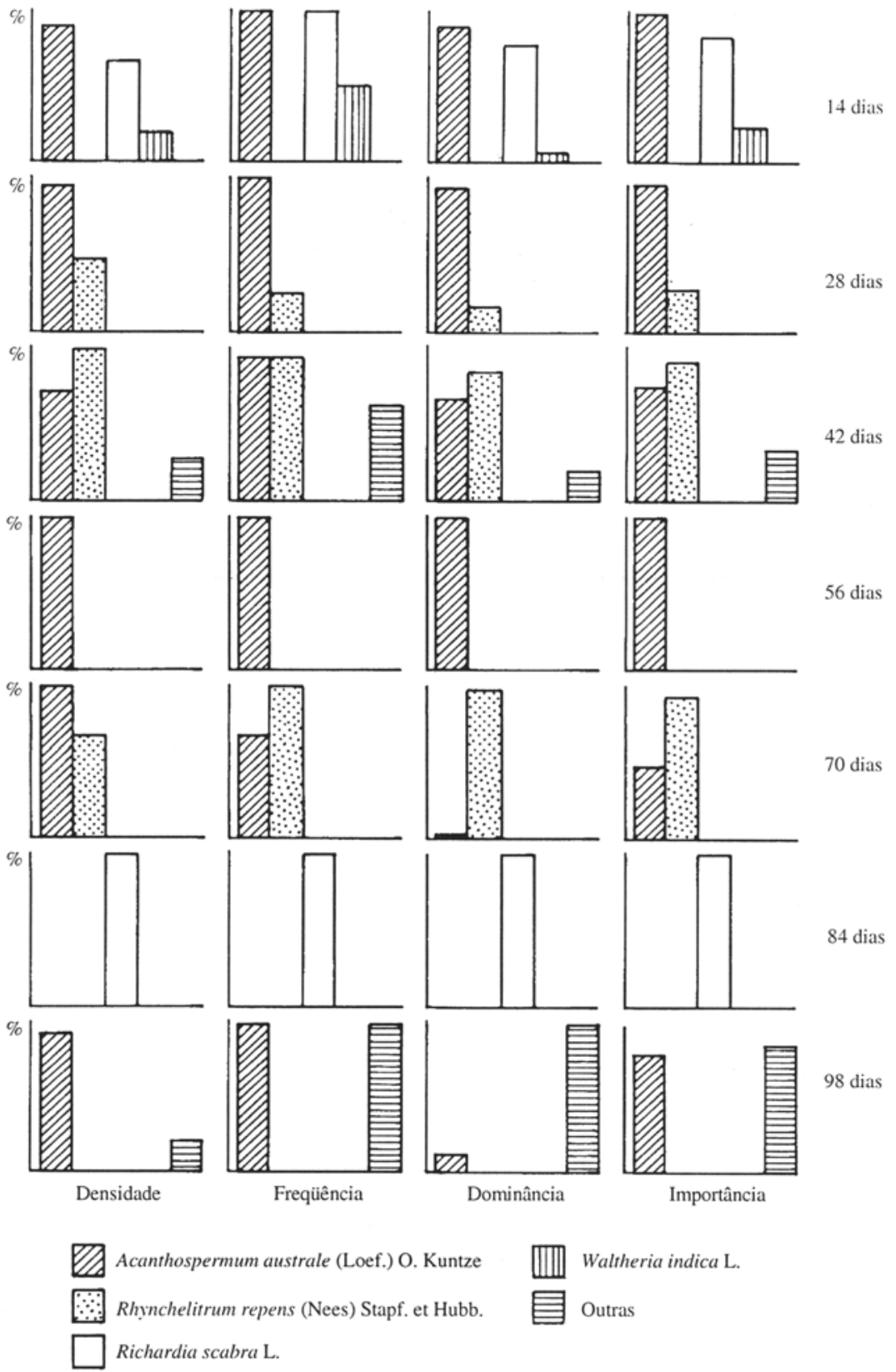

Figura 2 - Densidade, frequiência, dominância e importância relativas das principais espécies componentes da comunidade infestante, avaliadas por ocasião da colheita do amendoinzeiro em Mogi-Guaçu - 1985/86, em parcelas mantidas no limpo por períodos crescentes a partir do início da cultura. 

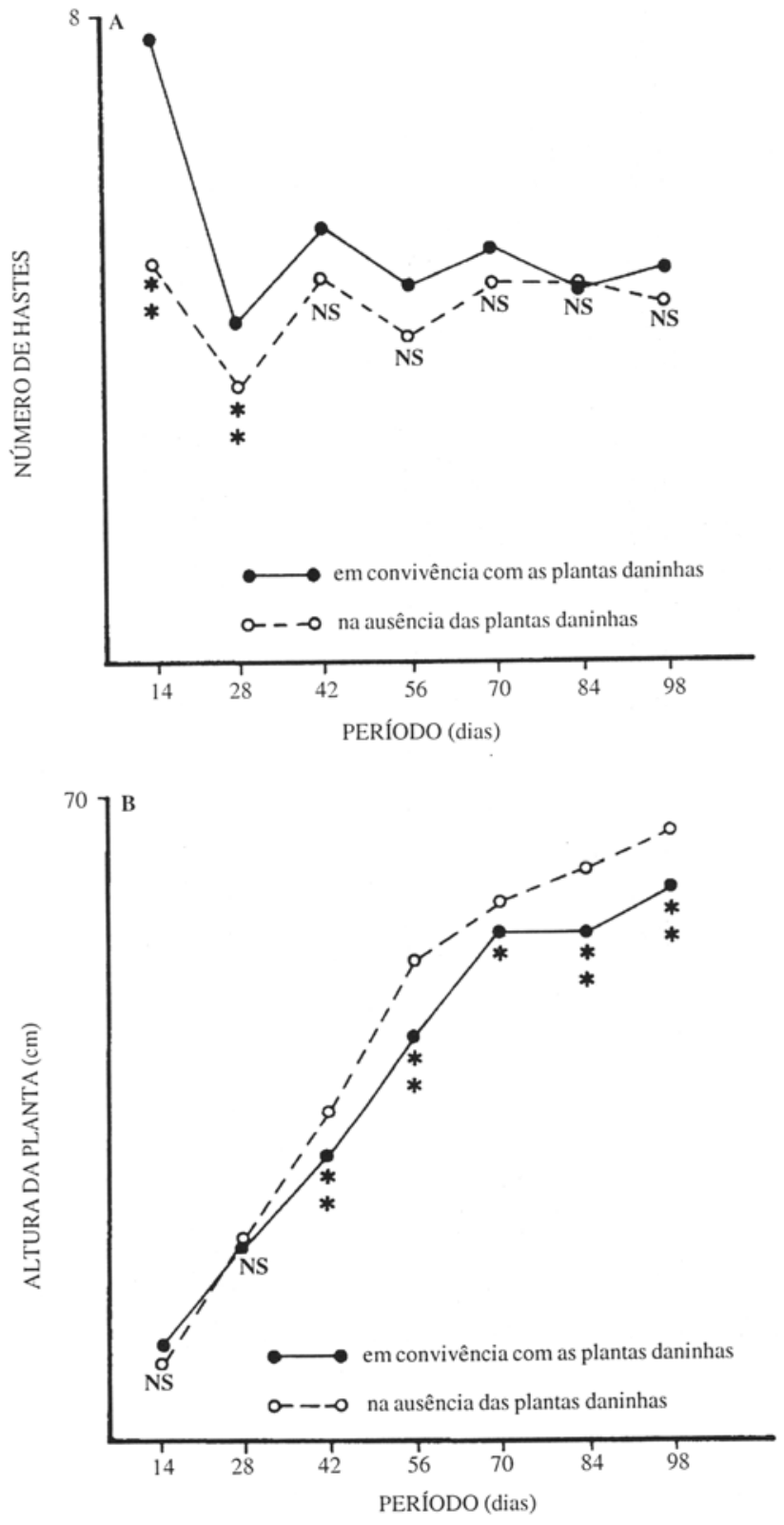

Figura 3 - Efeitos da interferência da comunidade infestante sobre o número de hastes (A) e a altura da planta (B), em plantas de amendoinzeiro (Arachis hypogaea L.), em diferentes períodos de desenvolvimento da cultura; $\left({ }^{*}\right)$ significativo ao nível de $5 \% ;\left(^{* *}\right) 1 \%$ e (NS) não significativo pelo teste de Tukey; Mogi-Guaçu - 1985/86. 

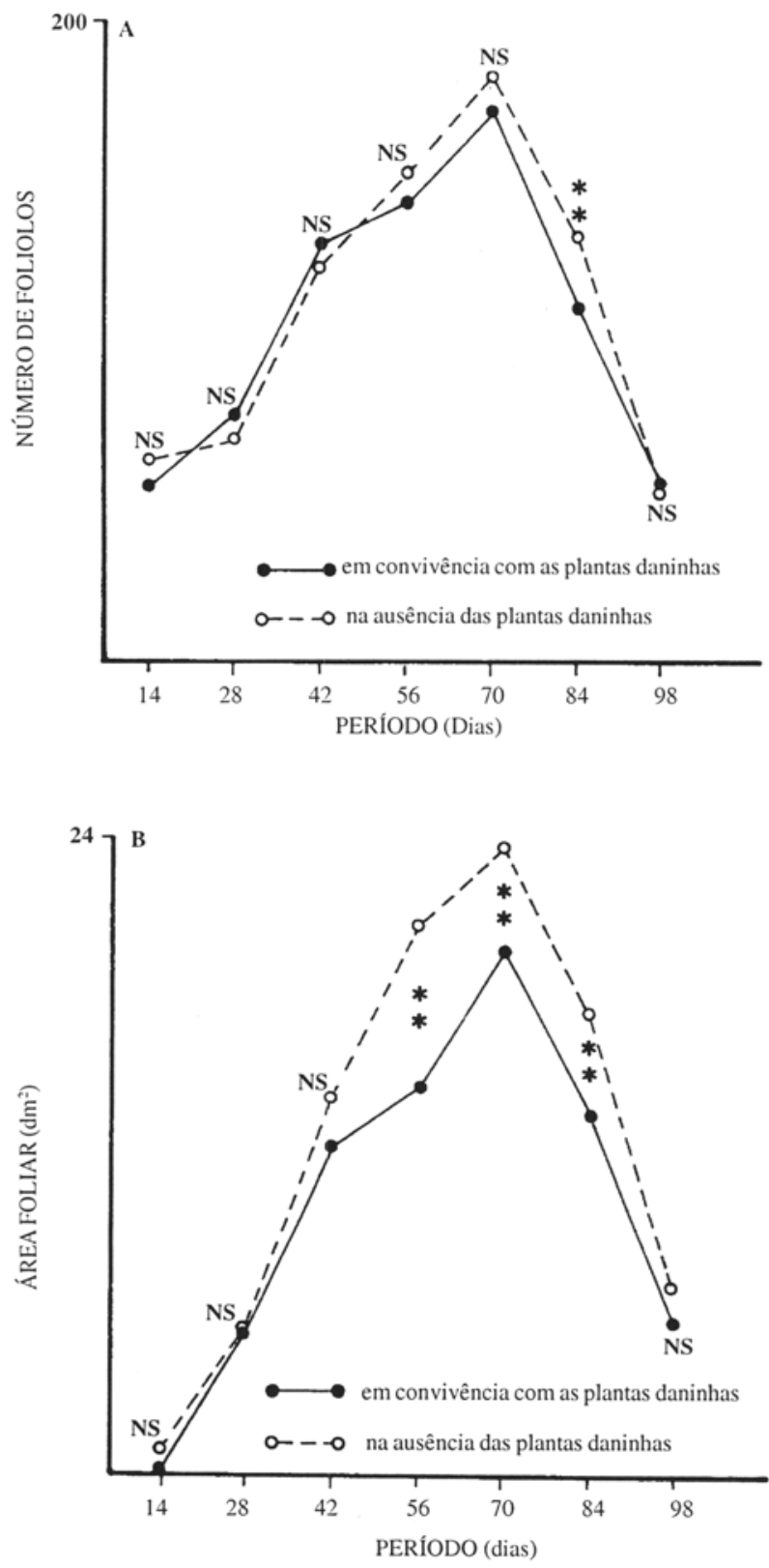

Figura 4 - Efeitos da interferência da comunidade infestante sobre o número de folíolos (A) e a área foliar (B) de amendoinzeiro (Arachis hypogaea L.), em diferentes períodos de desenvolvimento da cultura; $(*)$ significativo ao nível de 5\%; $\left(^{* *}\right) 1 \%$ e (NS) não significativo pelo teste de Tukey; Mogi-Guaçu - 1985/86. 

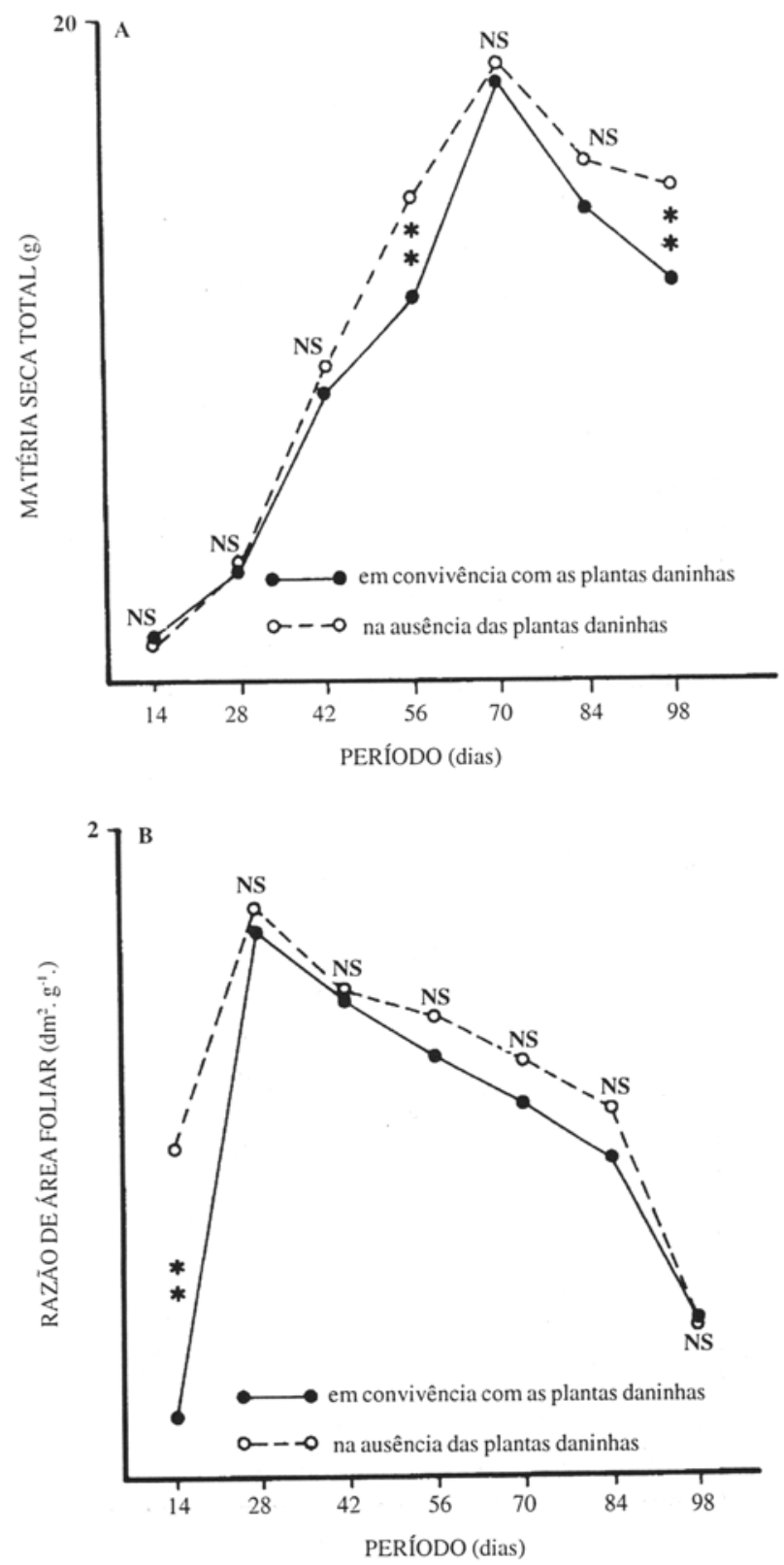

Figura 5 - Efeitos da interferência da comunidade infestante sobre a matéria seca total (A) e a razão de área foliar (B), de plantas de amendoinzeiro (Arachis hypogaea $\mathrm{L}$.), em diferentes períodos de desenvolvimento da cultura; $(*)$ significativo ao nível de $5 \% ;(* *) 1 \%$ e (NS) não significativo pelo teste de Tukey; MogiGuaçu - 1985/86. 
exceto na amostragem de 14 dias (Figura 5B), o que pode ter constituído um fato fortuito, desprovido de significado biológico, ou estar relacionado ao estímulo precoce de brotações laterais, porém às expensas das reservas cotiledonares, ainda presentes nesta fase da planta.

Os valores da taxa de produção de matéria seca por unidade de área de solo foram similares em ambas as situações (Figura 6A), exceto nas amostragens realizadas aos 56 dias, quando na condição "no mato" a taxa apresentou uma maior redução e aos 70 dias, na mesma condição, o amendoinzeiro apresentou grande taxa de produção de matéria seca . Nas diversas taxas estudadas, não foi possível aplicação da análise estatística tradicional devido à alternância de valores negativos e positivos, o que aumentava demasiadamente a homocedasticidade dos dados. Por isso optou-se pela simples comparação gráfica, avaliando-se apenas o nível de significância através das médias de tratamentos.

Tanto para taxa de crescimento absoluto (Figura 6A) como para taxa de crescimento relativo (Figura 6B), os valores observados nas duas condições foram bastante similares, alternando posições de magnitude e evidenciando pequena influência das plantas invasoras nestes importantes indicadores do comportamento do crescimento da planta cultivada. Tal fato também foi observado para a taxa assimilatória líquida (Figura 7A).

O número de frutos por planta foi sempre menor nas parcelas no mato, embora a análise estatística tenha acusado diferenças significativas apenas aos 70 e 98 dias.

Pelo observado na discussão dos resultados obtidos na comunidade infestante, algumas densidades observadas durante o experimento em que os efeitos da comunidade infestante foram mais drásticos, eram compatíveis com as densidades das plantas invasoras nos outros períodos. No entanto, é importante considerar o hábito de crescimento das principais invasoras na área: com exceção da $W$. indica, as demais eram de pequeno porte ( $R$. repens, $D$. teres e $B$. alata) ou de hábito de crescimento rasteiro ( $R$. scabra, A. australe). Deste modo, uma das principais formas de interferência a qual o amendoinzeiro é bastante suscetível, que é a competição por luz, não foi de significativa expressão neste ensaio.

Embora muitos desses parâmetros estejam sendo analisados pela primeira vez, em trabalhos desta natureza, alguns outros foram amplamente estudados e tidos como importantes indicadores de interferência da comunidade infestante na produção de grãos, principalmente o número de frutos por planta, que vários autores ponderam ser o principal componente da produção afetado pelas plantas daninhas (Ishag 1971; Pitelli 1980; Cazetta 1983; Pansani 1983; Peressin 1984; Gavioli 1985 e Martins 1988).

Não foram observados efeitos significativos dos tratamentos sobre a porcentagem de germinação das sementes de amendoim, que variou de $67,5 \%$ a $94,5 \%$, e sobre o índice de velocidade de germinação (IVG), com variação de 6,83 a 8,09. Os dados estão de acordo com Dajoz (1973) que afirmou que a competição reduz o número de dissemínulos por planta, mas não afeta a capacidade de sobrevivência de cada propágulo. 

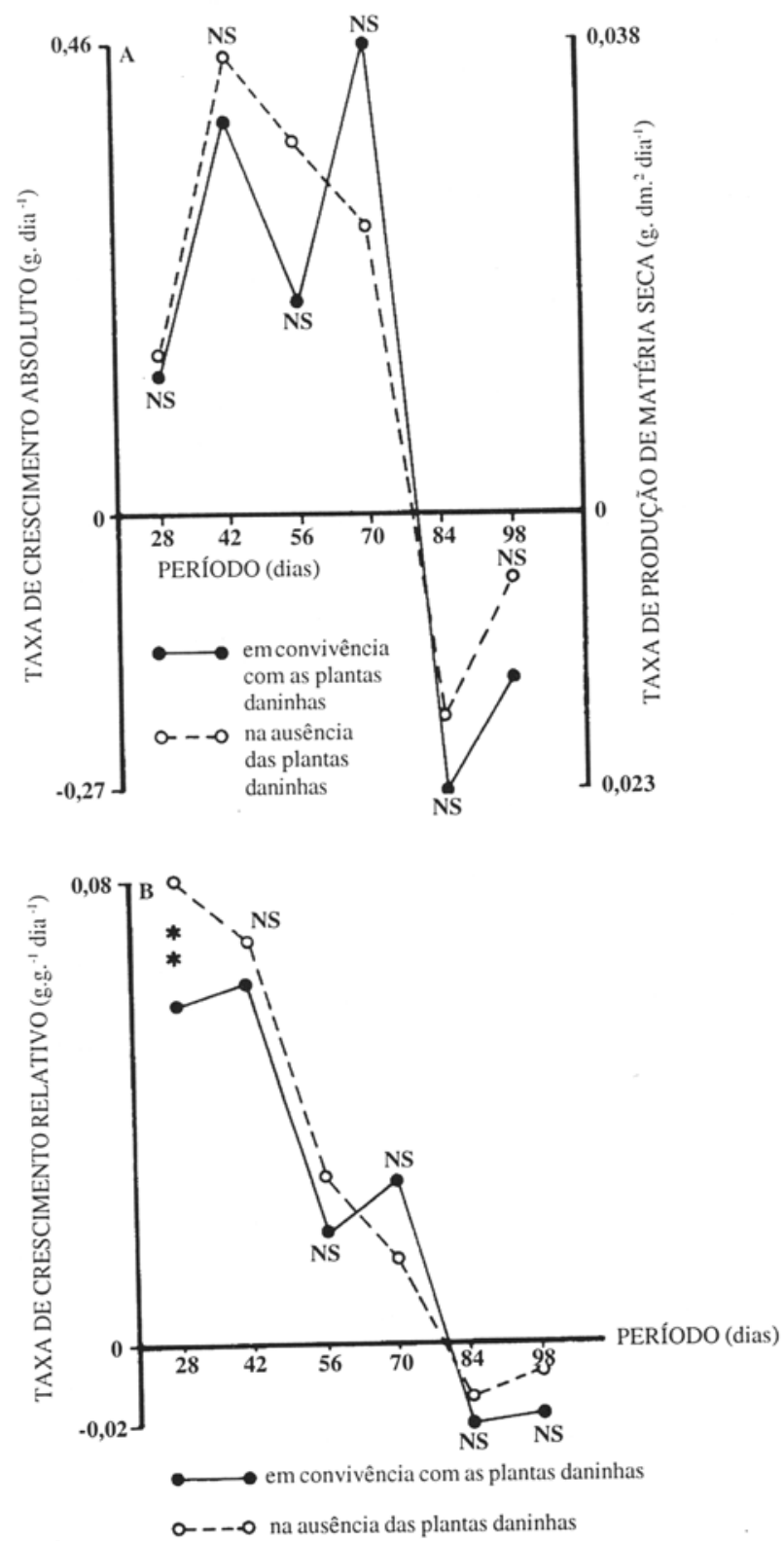

Figura 6 - Efeitos da interferência da comunidade infestante sobre a taxa de produção de matéria seca e a taxa de crescimento absoluto (A) e a taxa de crescimento relativo (B), de plantas de amendoinzeiro (Arachis hypogaea $\mathrm{L}$.), em diferentes períodos de desenvolvimento da cultura; $\left({ }^{*}\right)$ significativo ao nível de $5 \% ;\left({ }^{* *}\right)$ $1 \%$ e (NS) não significativo pelo teste de Tukey; Mogi-Guaçu - 1985/86. 

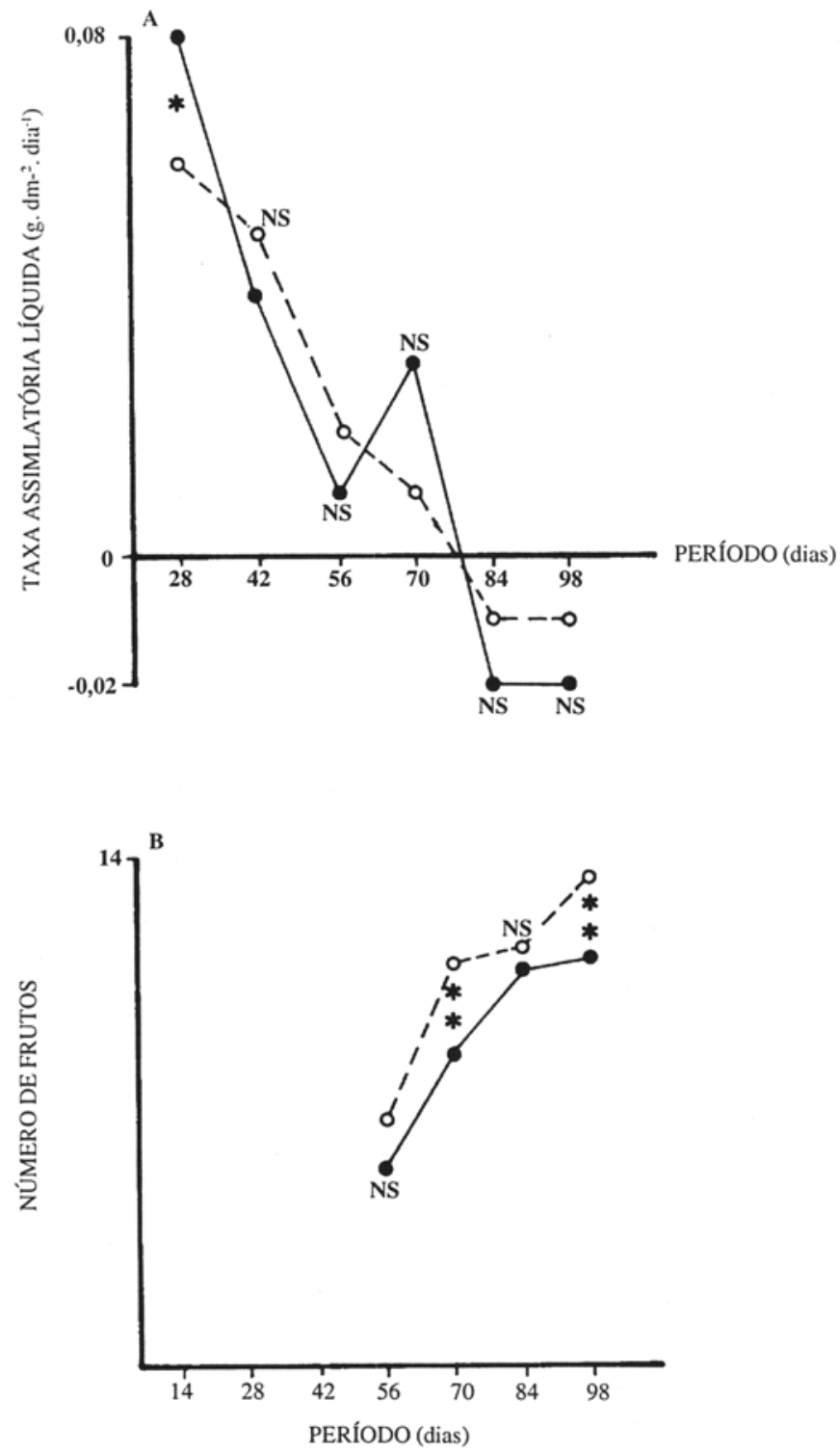

$\longrightarrow$ em convivência com as plantas daninhas

○- - 0 na ausência das plantas daninhas

Figura 7 - Efeitos da interferência da comunidade infestante sobre a taxa assimilatória líquida (A) e o número de frutos (B) de plantas de amendoinzeiro (Arachis hypogaea L.), em diferentes períodos de desenvolvimento da cultura; $\left({ }^{*}\right)$ significativo ao nível de $5 \% ;\left({ }^{* *}\right) 1 \%$ e (NS) não significativo pelo teste de Tukey; Mogi-Guaçu - 1985/86. 


\section{Agradecimentos}

Os autores agradecem a Engenheira Agrônoma Lilian Maria Asperti, Assistente Técnico da Seção de Ecologia pelo auxílio prestado na revisão do trabalho e das figuras aqui apresentadas.

\section{Referências bibliográficas}

Barbosa, J.M. 1983. Recomendações de substratos ideais para germinação de sementes de oito espécies nativas. Anais do XXXIV Congresso Nacional de Botânica, Porto Alegre, p. 427-431.

Barbosa, L.M. 1989. Efeitos de períodos de controle e convivência de plantas daninhas no desenvolvimento, absorção de nutrientes, incidência de fungos micorrízicos vesículo-arbusculares e produtividade na cultura do amendoinzeiro (Arachis hypogae L.). Tese de Doutorado, Agron.-Fitotecnica, FCAV/UNESP, Jaboticabal.

Bianco, S. 1978. Matocompetição em amendoim das "secas" sob diferentes condições de adubação. Trabalho de Graduação, FCAV/UNESP, Jaboticabal.

Blanco, H.G. 1972. A importância dos estudos ecológicos nos programas de controle das plantas daninhas. O Biológico, 38:343-350.

Buchanan, G.A.; Hauser, E.W.; Ethredge, W.J.; Cecil, S.R. 1976. Competition of Florida beggarweed and sicklepod with peanuts. II. Effect of cultivation weeds and SADH. Weed Science, 24:29-39.

Cazetta, J.O. 1983. Efeito de condições culturais sobre algumas características bromatológicas de grãos de amendoim (Arachis hypogaea L.) Trabalho de Graduação, FCAV/UNESP, Jaboticabal.

Dajoz, R. 1973. Ecologia Geral - São Paulo, Editora Vozes.

Drenan, D.S.H. \& Jennings, E.A. 1977. Weed competition in irrigated cotton (Gossypium barbadensis L.) and ground-nut (Arachis hypogaea L.) in the Sudan Geriza. Weed Research, 17:3-9.

Feakin, D. 1973. Pest control in groundnuts. 3. ${ }^{\mathrm{a}}$ ed. London, Centre for Over-seas Pest Research.

Gavioli, V.O. 1985. Efeitos da época e extensão do período de controle de plantas daninhas sobre a cultura de amendoim (Arachis hypogaea L.), em duas épocas de semeadura. Trabalho do Graduação, FCAV/UNESP, Jaboticabal.

Hamdoun, A.M. 1977. Competitive effects of weeds upon growth and yield of cotton, groundnuts and sorghum in the Kenana area of the Sudan. Zeitschrift fur Pflanzenkrankheiten un Pflanzenschutz, 84:509-515, 1977. Apud: Weed Abstracts, 27(7):2324.

Hammertonn, J.L. 1976. Problems of herbicide assessment in peanuts in Jamaica. Weed Research, 16:2735 .

Hauser, E.W. \& Parham, S.A. 1969. Effects of annual weeds and cultivation on the yield of peanuts. Weed Research, 9:192-197.

Hauser, E.W.; Buchanan, G.A.; Ethredge, W.J. 1975. Competition of Florida Beggarweed and Sicklepod with peanuts. I. Effects of periods of weed free maintenance on weed competition. Weed Science, 23:368-372.

Ishag, H.M. 1971. Weed control in irrigated groundnuts (Arachis hypogaea L.) in the Sudan Geriza. Journal of Agricultural Sciences, 77:237-241.

Martins, D. 1988. Estudos da interferência das plantas daninhas na cultura do amendoim. Efeitos de espaçamento, variedade e período de convivência. Dissertação de Mestrado, FCAV/UNESP, Jaboticabal.

Noda, K. 1977. Integrated weed control in rice. In: Fryer, J.D. e Matsumaka, S. (eds.) Integrated control of weeds. University of Tokyo Press, Tokyo. p.17-46.

Pacheco, R.P.B. 1977. Duração do período de competição de malerbas com a cultura do amendoim das águas (Arachis hypogaea L.). Ciência e Cultura, 29:599. (Suplemento).

Pansani, L.C. 1983. Efeitos de períodos de matocompetição sobre o crescimento e produtividade da cultura do amendoim "das secas" (Arachis hypogaea L.). Trabalho de Graduação, FCAV/UNESP, 
Jaboticabal.

Peressin, V.A. 1984. Efeitos do consórcio entre as culturas de arroz e do amendoim na presença e na ausência da comunidade infestante. Trabalho de Graduação, FCAV/UNESP, Jaboticabal.

Pitelli, R.A. \& Neves, A.S. 1978. Efeitos da competição das plantas daninhas sobre algumas características morfológicas e agronômicas de plantas de soja. In: Seminário Brasileiro de Herbicidas e Ervas Daninhas, $12 .^{\circ}$ Fortaleza, 104p.

Pitelli, R.A.; Ferraz, E.C.; De Martins, G. 1981. Efeito do período de matocompetição sobre a produtividade do amendoim (Arachis hypogaea L.). Planta Daninha, 4:110-119.

Pitelli, R.A. 1980. Efeitos do período de competição das plantas daninhas sobre a produtividade do amendoim (Arachis hypogaea L.) e o teor de macronutrientes em suas sementes. Dissertação de Mestrado, ESALQ/USP, Piracicaba.

Pitelli, R.A. 1983. Biologia de plantas daninhas. In: 5. ${ }^{a}$ Semana de Herbicida, Bandeirantes, 1983. Bandeirantes Fundação Faculdade de Agronomia "Luiz Meneguel", p.01-09.

Pitelli, R.A. 1987. Efeitos de períodos de convivência e controle das plantas daninhas no crescimento, nutrição mineral e produtividade da cultura da cebola (Allium cepa L.). Tese de Livre Docência, FCAV/UNESP, Jaboticabal.

Struffaldi de Vuono, Y.; Barbosa, L. M. \& Batista, E. A. 1982. A Reserva Biológica de Moji-Guaçu. In: Anais Congresso Nacional de Essências Nativas, Campos do Jordão. São Paulo, 16A(1):548-558.

York, A.C. \& Coble, H.D. 1977. Fall panicum interference in peanut. Weed Science, 25:43-47. 